\title{
UMA REFLEXÃO SOBRE PERCEPÇÃO DE ASPECTO
}

\section{João José R. L. de Almeida \\ Universidade Estadual de Campinas - UNICAMP}

\begin{abstract}
Resumo
Este artigo defende que o esclarecimento dos nossos proferimentos acerca de lógica, regras, visão de mundo e normatividade do significado ajuda a contribuir no combate à exclusão social porque incide sobre pressupostos influentes e potencialmente imiscuídos até mesmo em políticas pedagógicas de inclusão, ajudando a dissolvê-los. O método preconizado é o de uma etnografia dos nossos conceitos.
\end{abstract}

Palavras-Chave: lógica; crença; incomensurabilidade; percepção de aspecto; autocrítica.

\begin{abstract}
This paper argues that the clarification of our statements about logic, rules, worldview and normativity of meaning helps to contribute to the fight against social exclusion because it can have an imprint against relevant and potentially entangled assumptions even within pedagogical policies of inclusion, helping to dissolve them. The advocated method is an ethnography of our concepts.
\end{abstract}

Keywords: logic; belief; incommensurability; aspect perception; self-criticis 


\section{Interconexões entre lógica e psicologia}

Uma das acepções mais comuns da palavra "lógica" é a que se deriva de sentenças do tipo "Fulano rege-se por uma lógica particular, diferente das demais" ou "Deveríamos ser guiados por uma outra lógica, em vez da que habitualmente seguimos". Se pudermos substituir essas frases por "Fulano tem um pensamento diferente dos demais" e "Deveríamos mudar de pensamento", respectivamente, então não haverá dúvida de que, naqueles sentidos, o substantivo "lógica" tomou o lugar da locução "pensamento". E, se isso ocorreu, o termo pode eventualmente abraçar consequências ligadas àquilo que concebemos apenas para esta última palavra. Uma delas, talvez a mais notória, é o enrijecimento do que seria apenas uma técnica de controle de inferências entre sentenças, passando a desempenhar furtivamente o papel de fundamento.

Inicialmente, é preciso ressaltar que sentenças que confundem lógica com pensamento circulam amplamente na nossa vida diária e não são apenas visíveis nas conversas entre pessoas que adquiriram algum grau de cultura ou em textos jornalísticos. Elas também se enraízam profundamente na filosofia, nas ciências humanas e até mesmo numa área tão exata da ciência quanto a inteligência artificial. Kant, por exemplo, expoente da crítica e certamente o maior filósofo do século das luzes, estabelece uma inter-relação orgânica entre "lógica" e "pensamento" no momento em que afirma que a faculdade do entendimento tem que ser necessariamente governada, nas suas operações, pelas leis fundamentais da lógica. Claro, as distinções e aplicações na sua obra são mais finas e sutis do que parece à primeira vista. Há lógica pura e aplicada, e a relação mais fundamental entre lógica e pensamento se dá no âmbito da primeira. Na Crítica da Razão Pura (Kant, 1989 [1787]), ao abrigar-se sob o pressuposto da necessidade, o filósofo torna inexorável que não seja senão a lógica geral a essência do que constitui a teoria pura da razão, pois aquela se "abstrai totalmente do conteúdo do conhecimento do entendimento e da diversidade dos seus objetos e refere-se apenas à simples forma do pensamento" (cf., p. 90 [A 54]). Do ponto de vista de uma forma a priori e pura da razão, portanto, independente de uma psicologia no sentido empírico, lógica e pensamento mantêm uma cumplicidade absoluta se nos restringimos exclusivamente ao reino impoluto da necessidade.

Nas ciências humanas, talvez a análise de Lévi-Strauss sobre os mitos ameríndios seja o mais significativo modelo dessa mesma espécie de conviç̧ão de que o pensamento necessariamente reduz-se a uma forma que envolve um conteúdo qualquer. A grande diferença entre o antropólogo e aquele filósofo é que o etnógrafo recusa o pensamento abstrato enquanto pretende circunscrever-se a uma "ciência do concreto" (Lévi-Strauss, p. 31). Para tanto, basta afigurar os termos da linguagem, supostamente nosso instrumental cognitivo por excelência, como um conjunto limitado de peças ou produtos já previamente elaborados a servir de utensílios para a confecção de uma bricolagem para fins sociais. Não são mais os significados ou conteúdos daquilo que se diz no mito, no relato ou no ritual o que realmente importa para descrever o que Lévi-Straus chama de "pensamento", mas as imagens ou significantes mediante os quais se tece uma narrativa cuja forma não será mais que um sistema de contrastes, correspondências, analogias e oposições, montado a partir de um 
conjunto finito e já disponível de peças, como em qualquer lugar do mundo. Teremos, então, o que Lévi-Strauss toma por uma "lógica concreta" (idem, p. 53). Por isso, o pensamento selvagem não é exatamente o pensamento do selvagem, mas muito mais aquilo que é selvagem no pensamento, por diferenciação com o pensamento domesticado, este já cultivado e subserviente a outros fins (ib., p. 245). Os sistemas dispostos nessas bricolagens são materialmente inconscientes, visceralmente ligados à existência humana coletiva, à necessidade de não morrer de fome e de manter um nível mínimo de subsistência. Seu propósito é organizar a vida, atualizar a sua manutenção, estabelecer suas possibilidades e interditos, de maneira que sua parte visível oculte suas pretensões invisíveis. "O pensamento selvagem ...constrói edifícios mentais que ...facilitam a inteligência do mundo" (ib., p. 291). A mitologia, o xamanismo, tem o mesmo tipo de pensamento concreto também explicado pela psicanálise e pelo marxismo com relação ao mundo moderno, que são arranjos coloridos e entrelaçados surpreendentes dos dados presentes e imediatos para finalidades determinadas à preservação do status quo. O pensamento é um sistema formal concretamente situado na história, forjado de elementos sensíveis e somente através destes operativo. Também o pensamento, para Lévi-Strauss, mas diferente de Kant, é, em essência, uma forma vazia de conteúdo.

$\mathrm{E}$ ainda, num quadrante muito diferente da ciência, este mais afeito à tecnologia, podemos encontrar o mesmo tipo de uso de sentenças. No artigo seminal de Turing sobre a inteligência artificial (cf. 1936), por exemplo, não há nenhuma economia de adjetivos e analogias para igualar o comportamento artificialmente construído da máquina ao que podemos entender por "pensamento":

Nós podemos comparar um homem no processo de computação de um número real a uma máquina que só é capaz de um número finito de condições $q_{1}, q_{2}, \ldots$, $q_{\mathrm{r}}$, que serão chamadas de "configurações- $m$ ". A máquina é equipada com uma "fita" (análoga a um papel) que corre através dela e é dividida em seções (chamadas de "quadrados"), cada uma delas capaz de carregar um "símbolo". Em um dado momento, haverá apenas um quadrado, digamos o $r$-ésimo, que carrega o símbolo $\mathrm{G}(r)$ que está "na máquina". Nós podemos chamar esse quadrado de "quadrado esquadrinhado". O símbolo no quadrado esquadrinhado pode ser chamado de "símbolo esquadrinhado". O "símbolo esquadrinhado" é o único do qual a máquina está, por assim dizer, "diretamente ciente". No entanto, ao alterar as suas configurações- $m$, a máquina pode efetivamente lembrar-se de algum dos símbolos que ela "viu" (esquadrinhou) previamente (p. 231).

Note-se, a bem da verdade, que quase sempre Turing coloca entre aspas as analogias que estabelece entre comportamento mecânico e processos psicológicos típicos do ser humano, como na afirmação de que a máquina está "diretamente ciente", e de que ela "viu", por semelhança funcional ao pensamento e à percepção. Mas em outros lugares em que há essa comparação, as aspas são despreocupadamente esquecidas, como no uso do verbo "lembrarse". Essa permuta, na realidade, é recorrente ao longo de todo o artigo (veja-se, por exemplo, os dez usos da expressão "state of mind" (estado da mente), com e sem aspas, nas páginas 
250, 251 e 253). O fato é que todo o entusiasmo transmitido pelo texto, mediante tais analogias com o pensamento humano, está contido na sugestão de que o computador pode pensar autonomamente com muito maior eficiência do que o homem, pelo menos no que se restringe à espécie de função recursiva indicada pelo artigo. De fato, o texto pretende dar a entender que o computador pode "pensar" por conta própria no escopo de uma tarefa finita para a qual há de dar uma resposta "sim" (verdadeiro) ou "não" (falso), embora seja feita claramente a ressalva que ele não pode decidir nada sozinho, por si mesmo, caso em que a previsão Gödeliana de incompletude se aplicaria e o paradoxo que ficou conhecido na literatura pela expressão técnica "halting problem", de cujos detalhes podemos prescindir neste artigo, impediria a resposta efetiva da máquina (cf. Sipser, 2013, p. 216-218; Penrose, p. 75-83).

Sob que justificativas pode Turing estabelecer essas analogias? Se seguimos a argumentação do texto, números computáveis são os que podem ser codificados em um sistema binário de 0's e 1's pela transformação de uma função (uma tabela de instruções) e de um argumento (a fita que serve de "input") em um análogo mecânico ou eletrônico. Turing, na realidade, aplica numa máquina a prova de Church de que todas as funções teóricas de números efetivamente calculáveis (ou seja, algoritmos) podem ser codificadas em termos binários. Mas, junto com a aplicação de funções recursivas a uma determinada mecânica, também está embrulhada no pacote a ideia de que cada configuração- $m$ é um estado da mente da máquina (cf. p. 251). Em outros termos, se quisermos, o que se insinua pelas formas de expressão utilizadas no texto é que cada inferência lógica simularia uma operação mental.

O elemento mítico também aqui presente, tal como em Kant e em Lévi-Strauss, é a imagem de que o pensamento foi abstraído e esvaziado de conteúdo para poder se constituir em tema da lógica. Neste tipo de concepção, que não seria mais do que logo adiante vou qualificar como "visão de aspecto", se estabelece uma solução de compromisso: o projeto crítico inicia-se a partir de um ponto insubmisso à crítica. Somente dali para diante é que vale o exame rigoroso e detalhado das evidências. Portanto, tem que haver um objeto bem circunscrito e previamente dado, o pensamento, reconhecido seja empiricamente, pela psicologia natural, seja transcendentalmente, mediante condições formais de possibilidade epistêmica, a partir do qual se pode obter, mediante um processo de fabricação determinado, um extrato a ser manipulado e adaptado para variados tipos de circunstância. Não se cogita em nenhum momento que, na realidade, o processo pode ter sido diferente, que o novo objeto que temos em mãos agora seria, antes, uma atividade ou um processo técnico e não um extrato do pensamento, como qualquer dos seus variados produtos, como a escrita, a música, os rituais da cultura ou da religião; e o pensamento, ele mesmo, não o objeto central dessas manifestações, mas somente um ponto de partida acrítico. Fazendo as vezes, assim, de uma fita métrica que não pode, ela mesma, ser por ela medida. Em vez de, então, algum desses novos objetos definirem a essência do pensamento, por que não supor que sejam por este definidos?

Naturalmente, uma pergunta formulada ainda nesses termos padece de ingenuidade atroz. Isso porque teríamos que levar em conta que Mill realizou justamente a inversão que 
Kant precluiu na sua Crítica. Este interditava a precedência epistêmica do psicológico ao lógico porque um fato psicológico não pode ser dado nem no sentido externo nem no sentido interno da intuição e, portanto, não pode também ser recebido pelas categorias do entendimento e render informação empírica decisiva. Em resumo, a psicologia, por não apresentar fatos empíricos, não pode ser uma ciência. Assim, só restou a Kant perscrutar por formas necessárias não informativas do pensamento. Já aquele, ao contrário do filósofo das luzes, sim, supunha a empiricidade de fatos psicológicos e, por conseguinte, da psicologia como forma válida de ciência indutiva natural. Como tal é que ela desempenha para Mill o papel de fundamento da lógica (cf. 1979 [1873]).

Por isso, a pergunta acima pela precedência possível do "pensamento" não pressupõe valor epistêmico, como em Mill, nem condições apriorísticas necessárias e universais, como em Kant, mas apenas a circunscrição de um conceito vago que ainda não determina bem se é um fenômeno individual ou social ou ambos. É claro que por esse viés já não mais teríamos nem definição nem uso objetivo para o vocábulo "pensamento". Mas não importa tanto neste momento que não saibamos precisamente o que é o pensamento, mais do que poder usufruir dos seus benefícios. O propósito deste artigo é antes sugerir um método, ao invés de uma fundamentação.

De fato, gostaria de contrastar não o pensamento, mas usos efetivos da palavra "lógica" com a definição técnica da matéria para retirar algumas conclusões a respeito do problema do diferente e do excluído. Pretendo percorrer muito brevemente conceitos filosóficos de argumento, crença e incomensurabilidade, para chegar a uma discussão a respeito do que podemos chamar de "normatividade do significado". Este é o esclarecimento que reputo essencial para aqueles que se preocupam com o tema da exclusão social; é a partir dessa base que podemos, a meu ver, sustentar uma etnografia das nossas categorizações.

\section{Lógica formal e informal}

Talvez possamos dizer que uma definição técnica de lógica sempre apresenta um sistema formal que obedece mecanicamente a regras precisas. Acompanhemos, por um momento, a definição extremamente econômica de lógica fornecida por Andrew Irvine: a de que esta "é o estudo da inferência correta" (1996, p. 9). Pelos limites estabelecidos no enunciado, podese depreender que a lógica comporta tanto inferências conclusivas quanto não-conclusivas. Pelas primeiras, chamadas de monotônicas, teremos um processo dedutivo e chegaremos a conclusões que expressam certezas; pelas últimas, estas chamadas de não-monotônicas, teremos processos abdutivos e indutivos, e chegaremos a conclusões contestáveis. Estes são pontos mais ou menos pacíficos, o que já não se pode dizer, por outro lado, acerca do significado da palavra "inferência". Evidentemente estamos a nos referir ao raciocínio humano, sob a suposição de que ele consiste de processos, ao modo de determinados passos claramente distinguíveis, e que esses movimentos obedecem também a certas regularidades visíveis etc. Mas, fora tudo isso que apenas parece evidente, quando se tenta esclarecer o que seria uma "inferência" ainda resta um cipoal taxonômico que periga ser tão exuberante 
quanto uma floresta tropical. Estas podem ser imediatas ou mediatas, podem ser lógicas, pressuposicionais ou conversacionais, e podem configurar casos de quantidade, qualidade, relação e modo, segundo o tipo de juízo proferido. Se não queremos nos aventurar nesse emaranhado categorial, mas se também, por outro lado, o entendimento de que a inferência é um processo de raciocínio ainda é, por vários motivos, muito insatisfatório, talvez nos contentemos provisoriamente se assentarmos a ideia de que se pode reconhecer inferências quando nos estão claras quais são as suas regras.

De fato, começamos com isso, com o enunciado de que a lógica consiste num sistema formal que obedece a regras mecanicamente precisas. Pois sem dúvida são essas regras que nos dirão se os passos inferenciais que executamos no sistema estão certos ou errados. E chegaremos a tal decisão mesmo sem saber precisamente o que é uma "inferência". Apenas é suficiente constatar, no sistema dedutivo, que um argumento é válido se for necessário que se todas as suas premissas forem verdadeiras, a conclusão também será verdadeira. Pois, se um argumento for válido, podemos dizer que suas premissas implicam necessariamente a sua conclusão. E assim, ao abrigo da necessidade lógica, poderemos estabelecer as regras de inferência. Regras que me garantem que se Maria só está feliz se João estiver com saúde, e João está, de fato, com saúde, então posso saber que a conclusão de que Maria está feliz é absolutamente válida. No sistema, ela é verdadeira se as premissas também o forem. E o que chamamos de inferência é apenas o processo que atendeu mecanicamente ao que dela esperávamos.

Esse sistema formal e absolutamente técnico pode também ser tratado pelo seu lado informal. Neste caso, ele não seria menos formal ou menos técnico, senão que passaríamos ao estudo do argumento tal como se apresenta naturalmente, em linguagem ordinária. Pois, mesmo na linguagem cotidiana, o argumento continua sendo uma estrutura lógica, uma vez que se compõe de premissas e conclusão, e segue as mesmas regras que estipulamos para inferências dedutivas convertidas em um simbolismo. A diferença será somente a de que unidades sentenciais não serão mais traduzidas por letras ou qualquer outro símbolo, mas permanecerá como sempre o tratamento das sentenças pela forma e não pelo conteúdo. No estudo do argumento, no sentido da lógica informal, lidamos, portanto, com sentenças tais como as do exemplo que evoquei acima, em linguagem natural e não simbólica.

O ponto importante aqui é que segue a estrutura lógica do argumento qualquer conjunto de evidências que se apresente para embasar uma hipótese, ou qualquer série de razões pelas quais justificamos uma crença. Desse modo, permite-se conceber uma crença qualquer, como, por exemplo, a de que a terra é plana, como uma conclusão que se segue, por inferência, de uma série de razões que lhe antecedem. Essa permissão especial, reparemos, ocorre sob o manto da ideia de necessidade.

\section{Crenças}

Sigamos, por conseguinte, pelos trilhos da necessidade, a direção de uma discussão lógica de crenças em vez de psicológica, embora não tenha dado nenhum fundamento para 
aquela matéria. Essa preferência, como disse, é apenas metodológica, uma vez que se pretende tomar conceitos psicológicos pela gramática dos seus usos. Neste sentido, então, assumimos que "crença" é a atitude que tomamos quando temos convicção de que algo é verdadeiro. Seja como resultado da influência ou persuasão de outras pessoas, seja por convencimento próprio, a crença é, em nossa visão, uma convicção firme que se revela mediante uma conduta inabalável com relação a conteúdo cognitivo na maior parte das vezes imperceptível para o agente. Atitudes como essas transparecem em sentenças do tipo "Não tenho cabeça para isso", que pressupõe a crença de que tenho uma cabeça, ou "Apesar de gostar de apresentações pelo Power Point, não sou o Deltan Dalagnol”, que pressupõe a crença de que não sou mesmo o referido procurador da república.

Uma característica notória da crença é a sua cogência. O intelecto assume por conta própria que se o conteúdo de uma crença é verdadeiro, necessariamente tudo que dela se derive é também verdadeiro. Em outras palavras, a atitude que se toma com relação à crença se transfere para o que dela se recolhe. Este processo é aquele que já qualificamos como inferência. Isso faz com que nossos juízos e tomadas de decisões não somente tenham a mesma força da necessidade lógica, mas também que não sejam facilmente derrogáveis. Na base da crença de que a terra é plana não há somente inferências, mas convicções muito firmes, por mais que isso nos cause perplexidade.

Suponha-se, por exemplo, que se pergunte a um colega de redação de Lois Lane, do Planeta Diário, se ela é realmente a namorada do Super-Homem. A resposta, com certeza, será "sim". Se novamente perguntamos a esse colega se ela não seria, na verdade, a namorada do outro colega de redação, o repórter Clark Kent, a resposta, mais uma vez com certeza, será "não". Independente de toda a bizantina discussão que daqui se segue a respeito da real articulação dos conceitos de sentido, referência e verdade (cf. Schwitzgebel, 2019), o ponto mais relevante para nós neste momento é que a referência é muitas vezes completamente opaca, e, para piorar, ligada a uma grande teia de crenças mais ou menos opacas. No entanto, justamente com base em crenças fazemos identificação e exclusão.

Identificação e exclusão aliadas à cogência redundam, numa versão extremada, no que reconhecemos popularmente por "crenças persistentes" ou "bolhas sociais". São conjuntos de crenças dotadas de uma resistência muito maior à derrogabilidade do que um padrão normal para a maioria das pessoas. Seria possível que o colega de Lois Lane, e ela mesma, acabassem aceitando reavaliar suas crenças diante das evidências em contrário, mas há muita gente que persiste com as suas mesmo em face das provas mais gritantes do seu equívoco. Este tipo de fenômeno, não muito raro, foi submetido a experimentos, analisado e reconhecido na década de 1950 pelo psicológo Leon Festinger e seus colaboradores, que o explicaram pela teoria da dissonância cognitiva. Trata-se da tendência de redução do desconforto cognitivo, mesmo em prejuízo da consistência, que se segue após a apresentação de incompatibilidades com determinadas crenças. Esse grupo de estudos avaliou que o primeiro compromisso do indivíduo é com a consistência interna, com a harmonia previamente estabelecida entre as crenças que o próprio individuo colecionou e organizou, ainda que em prejuízo da coerência com o mundo externo (cf. Festinger, 1957). 
Contudo, falamos aqui de indivíduos e de crenças bizarras que às vezes algumas pessoas sustentam. Outra coisa são as crenças coletivas, inerentes a culturas, que é a matéria que mais nos interessa.

\section{Incomensurabilidade?}

Uma outra espécie de pesquisa acerca da inconsistência entre crença e evidências empíricas, que ganhou notoriedade durante as décadas de 1960 e 1970 para explicar por que experimentos fortemente contrários a teorias científicas bem estabelecidas não logravam cumprir o preceito de falsificabilidade tão bem assentado na metodologia, foram os trabalhos apresentados por Thomas Kuhn (1996 [1962]) e Paul Feyerabend (1962) sobre a incomensurabilidade. Por meio desse conceito, esses autores também contribuíram, ainda que por rotas diferentes, para explicar por que abrigamos crenças de maneira tão profundamente arraigadas. O motivo pelo qual recordo suas ideias neste artigo é que a solução que propuseram vai nos servir também como modelo lógico de identificação e exclusão, se pudermos indicar previamente onde estão as falhas das suas explicações.

$\mathrm{Na}$ base do conceito de incomensurabilidade repousa a imagem de relações entre medidas ou grandezas que simplesmente não podem ser estabelecidas, conquanto possamos saber que as medidas das partes subsistem separadamente, cada uma com o seu próprio padrão de avaliação de grandeza física. O modelo clássico de segmentos incomensuráveis é o que se observa entre a diagonal e os lados de um quadrado. Estes não podem ser comparáveis porque a diagonal de um quadrado é um número irracional, e o lado, um número natural. Obviamente, a incomparabilidade entre as grandezas redunda na impossibilidade de tradução de uma grandeza na outra.

Kuhn e Feyerabend apegam-se mais ao consequente de intradutibilidade do que ao antecedente de incomparabilidade para fundamentar suas respectivas noções de incomensurabilidade. Se duas teorias científicas forem intradutíveis, então elas são incomparáveis. Se elas são incomparáveis, são incomensuráveis. Nestes termos, há uma falácia do consequente.

Vejamos. A teoria de incomensurabilidade de Kuhn vincula-se ao conceito de "paradigma". O paradigma newtoniano é incomensurável com o paradigma aristotélico, e o substitui a partir do século XVII; o paradigma de Lavoisier é incomensurável com o paradigma de Pristley, e o substitui a partir do século XVIII. Esses paradigmas não têm entre si um padrão comum de comparabilidade, segundo Kuhn, porque usam conceitos e métodos diferentes para resolver o que concebem de maneira diferente como problemas. Eles recortam e percebem a natureza de maneira diferente, e se dão tarefas e missões científicas diferentes, de acordo com o que concebem. No paradigma newtoniano, o movimento pendular é descrito em conformidade com os mesmos preceitos aplicáveis às leis do movimento em geral, ao passo que no paradigma aristotélico, o movimento pendular se concebe de acordo com a ideia de que corpos graves buscam o centro da terra; no paradigma de Lavoisier a combustão se explica pela interação do oxigênio com as moléculas da substância que foi aquecida; no 
paradigma de Priestley, a combustão se explica pela presença de um princípio calórico, o flogisto, presente na substância aquecida. Portanto, não há possibilidade de comunicação entre esses paradigmas, eles "veem" coisas diferentes. Conceitos, métodos e o que representa no paradigma um verdadeiro desafio científico estão interligados numa rede de valores e práticas de intervenção empírica que afeta decisivamente a perpepção do contínuo natural, este sim, comum entre os diferentes paradigmas. O trabalho de Kuhn consiste em explicar como se dão as mudanças de paradigma ao longo da história, posto que eles não se comunicam entre si.

O trabalho de Feyerabend é diferente. Está bem mais preocupado em postular uma política científica mais produtiva e fecunda do que poderia alcançar uma metodologia científica restritiva em qualquer sentido. Portanto, o foco do trabalho de Feyerabend são a descrição dos métodos, bem como o combate ao conservadorismo conceitual. Ele concebe sistemas conceituais da ciência como descrições da realidade. Um método de descrição da realidade é consistente com o sistema conceitual ao qual se vincula e é tão bom quanto qualquer outro método. $\mathrm{O}$ grande problema, para o autor, não são as descrições em si, mas suas interpretações realistas. As teorias são naturalmente incomensuráveis porque são, simplesmente, conceitualmente incompatíveis, não há um enunciado empiricamente correto que possa corrigir duas teorias incomensuráveis. Os enunciados teóricos e empíricos são internos ao esquema conceitual, assim como seus métodos de investigação e pesquisa. Somente uma pluralidade metodológica absolutamente não restritiva e plurilateral, uma proposta absolutamente anárquica em que qualquer processo seja válido, ampliaria nosso conhecimento da realidade.

Kuhn e Feyerabend têm, no entanto, pontos filosóficos em comum. Para ambos não há tradução possível entre duas teorias científicas incomensuráveis. Ou talvez, uma tradução como essa, se fosse possível, ficaria bastante prejudicada pela opacidade absoluta de significados decisivos para a correta interpretação do usuário da língua. Justamente essa suposição foi atacada por Davidson, que demonstrou que a intradutibilidade obriga a pensar que uma teoria científica é como uma espécie de esquema conceitual que acolhe e organiza dados recebidos do mundo empírico (cf. 1984, p.189). Para ele, uma concepção como essa não é nem defensável nem inteligível. Não passa de um dos dogmas do empirismo, o terceiro, ao lado do reducionismo e da distinção analítico-sintético já criticados anteriormente por Quine (cf. 1953). Uma das suas muitas formulações é a tese de Sapir-Whorf de que a linguagem é não só um instrumento de comunicação, mas produz uma determinada organização da experiência. Assim, cada língua numa comunidade de falantes comportaria uma visão de mundo diferente. O que se designa como "neve" numa língua Inuit, como a de vários grupos de esquimós, seria incomensurável com o mesmo termo proferido no português do Brasil, porque aqueles habitantes do Alasca, Canadá e Groenlândia teriam uma organização do mundo empírico completamente diferente da nossa. 


\section{O ver como}

No aspecto geral, concordo com a avaliação de Davidson de que uma linguagem é comparável com outra porque a sua relação com o mundo é interna. Talvez seja mais factível admitir que a linguagem já seja dada em articulação com o empírico do que supor que ela se refira ao mundo como uma entidade autônoma e externa. Assim, pelo menos evitamos o paradoxo relativista incutido na hipótese da incomensurabilidade. Na perspectiva pragmática de Davidson teríamos que lidar com opacidades semânticas como casos em que a resolução de dissonâncias cognitivas se dá por apelo à semântica extensional, isto é, pela referência às classes que satisfazem os termos aos quais se aplicam as sentenças. Dito de outro modo, a interpretação radical proposta por Davidson, que postula uma solidariedade entre linguagem e mundo, possibilita a aplicação de um princípio de caridade na comunicação pelo qual supomos imediatamente que a maioria das crenças sustentadas pelo interlocutor são verdadeiras pela simples observação do uso da linguagem em um contexto determinado. Por aqui reparamos que aquela distinção entre condições transcendentais puras e aplicadas, tão ao gosto de Kant, desapareceu. Elas são, tão somente, condições a priori.

A interdependência recíproca entre linguagem e mundo é o elemento que permite a compreensão de que equívocos assertóricos, como quaisquer outros, existem, mas são eventualmente corrigidos a longo prazo, e de que a comunicação humana potencialmente se ajusta à diminuição de ruídos, e não o contrário, pelo estabelecimento de equivalências na linguagem. Não haveria, portanto, incomensurabilidade, ainda que haja interferências na fluidez da comunicação. Precisamente na interação frequente e contínua com o mundo, Lois Lane poderia chegar a descobrir que Clark Kent era, na realidade, o seu namorado, a saber, o próprio Super-Homem.

Vamos utilizar estes dois exemplos da Gestalt, que são os mesmos aos quais Kuhn e Feyerabend recorrem para defender a hipótese da incomensurabilidade. Nosso objetivo é deixar um pouco mais claras quais são as condições envolvidas na semântica pragmática proposta por Davidson:
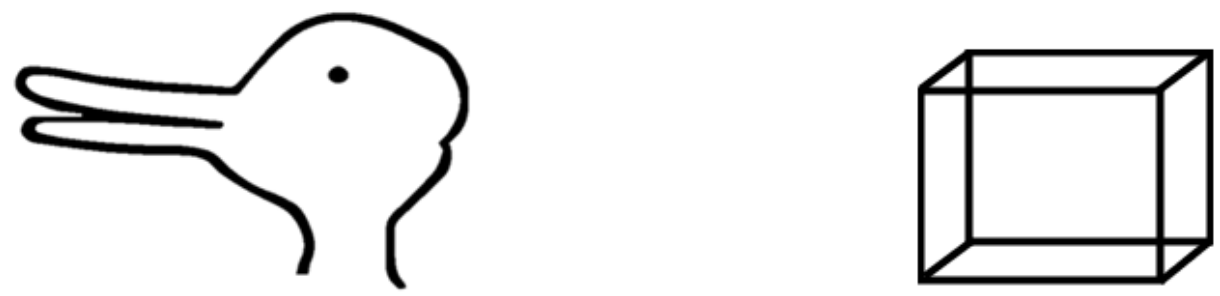

Suponhamos que para uma comunidade linguística a primeira figura representasse um pato e a segunda figura, um cubo cuja face frontal é mais baixa que a face posterior. Numa outra comunidade linguística, contudo, a primeira figura representaria um coelho e a segunda 
seria um cubo cuja face frontal é mais alta que a posterior. Concluiríamos que ambas as comunidades recebem exatamente os mesmos estímulos perceptivos, mas organizam a experiência empírica de modo completamente diferente. No entanto, como os conceitos divergentes em ambas as comunidades são ao mesmo tempo verdadeiros, no sentido da correspondência entre o referente e a palavra designativa, é possível que neste ponto, na admissão do pressuposto de que a relação entre linguagem e mundo fosse externa, não teríamos senão como inferir que a comunicação entre as duas comunidades fosse nula ou inexistente ou, então, pelo menos bem mais difícil de realizar do que conseguir convencer Lois Lane de que Clark Kent é realmente o Super-Homem. Pela redução ao absurdo, no entanto, segue-se que o pressuposto internalista é mais factível que o externalista. E, neste sentido, que a relação de correspondência entre linguagem e mundo deva ser, igualmente, interna.

Como não cairíamos no relativismo? Segue-se também que o pressuposto do relativismo é o externalismo, dado que esta ideia só faz sentido para quem está imune a efeitos semânticos, seres sublimes que pairam acima do mundo e da linguagem e podem contemplálos de um ponto de vista neutro, como as divindades, por exemplo. Para seres humanos, entretanto, cuja participação nas vicissitudes da vida apresenta-se de modo imanente, obrigase logicamente a supor este tipo de inter-relação:

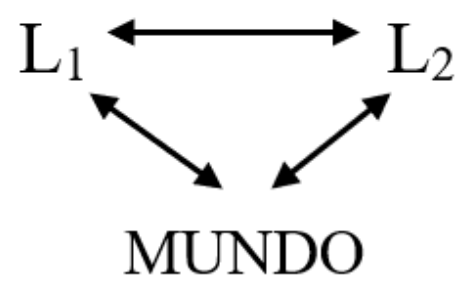

Nossa percepção do mundo deve ser filtrada por um conjunto de crenças forjadas e incutidas ao longo do nosso desenvolvimento intelectual e em interação com a sociedade e a cultura na qual estamos imersos. E ainda que este tema seja amplamente complexo, seus detalhes sejam objeto de constante debate, não se deve desconsiderar tampouco que processos como esse mostram que a mente humana funciona como uma máquina de categorização, no sentido de que identificamos e classificamos continuamente objetos e eventos que formam a base, em termos de condições necessárias e suficientes, da nossa organização cognitiva (cf. Cohen \& Lefebvre, 2005, p. 2-15).

Mas como, por questões de método, não retroagimos ao psicológico como fundamento de argumentos filosóficos, ficaremos circunscritos a observar que um dos resultados dessa inter-relação entre mente, linguagem e mundo, que nos leva constantemente a identificar e discriminar objetos e eventos, pertence a uma família de problemas filosóficos denominada 
como "visão de aspecto". A expressão refere-se a uma gama variada de discussões, levadas a cabo por Wittgenstein ao longo de todos os seus escritos, a respeito de múltiplas e peculiares formas de solidariedade entre o lógico e o psicológico. A ideia básica de Wittgenstein seria a de que dados empíricos são organizados em morfologias compreensivas que conferem não somente um enquadramento perceptivo determinado para o usuário, mas também um conjunto de regras e interpretações a respeito de como utilizá-lo na vida prática (cf. Wittgenstein, 2011, p. 44-47).

Regras como essas nos ensinariam que, para ver o pato, teríamos que considerar que o lado esquerdo da figura representa o seu bico, e uma pequena reentrância que se observa ao lado direito da figura, é apenas a forma imperfeita da parte de trás da sua cabeça. Para ver o coelho dentro da mesma configuração empírica, teríamos que seguir regras totalmente diferentes. O importante a observar neste contexto é que não podemos ver as duas figuras ao mesmo tempo, só uma de cada vez, cada uma de acordo com as suas próprias regras e sistemas de interpretação e aplicação. Talvez haja gente que, mesmo com a disponibilidade de novas regras, ainda inéditas para si, só consiga ver uma das figuras e nunca a outra. Neste caso, teríamos uma cegueira do aspecto. A possibilidade da mudança de aspecto, contudo, estaria condicionada decerto a fatores pragmáticos ligados ao poder de persuasão, que envolve elementos que vão muito além das regras e da lógica, propriamente ditos. Em outras palavras, isso quer dizer que a interação linguística e a ação mútua das diferentes crenças e forças pragmáticas, bem como o seu compartilhamento, depende crucialmente do diálogo.

\section{Filosofia e etnografia}

A constituição, o desenvolvimento e a complexificação da lógica, bem como a compreensão que hoje formamos sobre seguimento de regras e normatividade do significado, são realizações obtidas após décadas, e, às vezes, séculos de embates dialógicos. Sem que possamos logicamente compreender o que alcançamos até agora como um estágio evolutivo superior ou mais alto que o antigo, pois, conforme argumentamos, não dispomos de um padrão de medida externo para aferir um resultado como esse, o estado atual da questão apenas reflete as movimentações internas da área depois de decorrido algum tempo. Do que se infere que o diálogo não é uma atividade simples, nem direta, nem fácil. Idealmente supõe a existência de uma arena parlamentar em que todas as vozes estejam representadas com igualdade de direitos, supõe também a constituição de práticas diplomáticas e de negociação política na constituição dos diálogos, e sua existência condiciona-se, do mesmo modo, ao armistício e ao respeito entre os interlocutores. Mas na vida concreta uma situação como essa não existe em nenhum lugar. Trata-se apenas de um ideal regulativo ligado à prática argumentativa, ela mesma se realizando no meio de tantas dificuldades, obstáculos e interrupções, que não dariam nenhum suporte coerente ao conceito de racionalidade comunicativa (cf. Habermas, 1982).

Assim, o que se propõe com o conceito de visão de aspecto é a descrição da gramática ou conjunto de regras que engloba uma totalidade compreensiva ligada a uma prática. A 
gramática, por sua vez, é somente uma morfologia arbitrária que institui possibilidades e impossibilidades em conjunto com regras de transformação. Voltamos aqui àquele reino da necessidade lógica que abriga o que costumamos chamar de "pensamento". Mas não se trata agora nem de uma tese realista sobre a prática argumentativa nem da proposição de um idealismo transcendental. Por conseguinte, não há compromisso com qualquer hipótese sobre a racionalidade humana ou sobre o fundamento lógico do pensamento, mais do que com simples fatos colecionados pela história natural dos seres humanos a respeito do que se admite como correto e verdadeiro em certos juízos proferidos em determinados lugares ou épocas, e também como juízos como esses diferem significativamente ao longo da história ou em outras comunidades humanas.

A visão de aspecto, vencida a hipótese da incomensurabilidade, não é nada mais do que um objeto de comparação. Sua finalidade é facilitar o desencobrimento e a autocrítica acerca da maneira como vemos as coisas. E é precisamente neste ponto que ela pressupõe o dialogismo. Antes de estar comprometido com a ideia de racionalidade comunicativa, o modelo mais adequado para compreender esta proposta é a investigação etnográfica. Uma etnografia autocrítica, evidentemente. Não uma etnografia que tome o outro como o primitivo (Frazer), ou que tome o encontro com o outro pela descrição de uma estrutura universal (LéviStrauss), ou que tome a cultura como a leitura de um texto (Geertz). Essas formas de etnografia ainda encobrem a visão do outro com véus interpretativos apriorísticos. Neste sentido, a investigação da visão de aspecto deve ser uma descrição aberta, despreparada em certo grau e ao máximo desprovida de preconceitos, a fim de ressaltar contrastes resultantes de encontros surpreendentes, estranhos, incômodos ou deslocadores com o outro. Esses contrastes são o nosso objeto de comparação, são pontos de autocrítica e promotores de diálogo. Não são fundamento de ontologias.

Os índios Kadiwéu, num passado ainda não tão longínquo, costumavam distinguir seres humanos de animais pelo fato de que estes não usavam roupas nem calçados. Os índios Bororo, Guató e Knikinao, seus vizinhos, assim como as crianças até uma certa idade, nem sempre usavam roupas e calçados. Desse modo, uma marca empírica como a nudez possibilitava, para os Kadiwéu, dispensar tratamento diferenciado para essas etnias e para crianças muito pequenas. Os Kadiwéu capturavam e escravizavam seus vizinhos para obrigálos a cumprir tarefas consideradas menos nobres como plantar, colher e ocupar-se dos afazeres domésticos, assim como, por outro lado, tampouco garantiam defesa plena da vida de suas próprias crianças ainda muito pequenas (cf. o depoimento de Domingos Soares em Vinha, 1999, p. 129; e o relato "Kadiweu/História de Antigamente" em Tycho Brahe Framework, 2019). Outros fatores provavelmente também estavam em jogo, como maior poder bélico que os rivais, necessidade de conservar seu complicado sistema hierárquico, necessidade de sobrevivência da comunidade como um todo em detrimento dos indivíduos mais frágeis, eventualmente portadores de problemas de saúde etc. Mas não importa tanto, para os nossos propósitos, as condições suficientes do conceito de humano entre os Kadiwéu, quanto o fato de sempre haver identificação e exclusão.

Esta é a matéria, por excelência, da educação especial. O que proponho, por isso, é um método de investigação dos problemas pedagógicos relativos à exclusão de seres humanos, 
da sua identificação como classe, que ao mesmo tempo cuide de não reintroduzir subrepticiamente os próprios problemas que pretende solucionar, quase que somente por causa de uma confusão desapercebida entre pensamento e lógica. Um método cujo modelo é a investigação etnográfica, que se vale do lógico apenas como objeto de comparação, não como fundamento, é uma ferramenta assim. Seu valor é o de reconhecer os contrastes, reconhecer a nossa própria lógica e promover a autocrítica como meio de inclusão do diferente. $\mathrm{O}$ fato de que não podemos pensar ilogicamente vale apenas como descrição gramatical, como visão de aspecto. O reino da necessidade lógica e da cogência das nossas crenças vige apenas no interior da morfologia que nos abriga. Por mais verdadeiras que sejam as nossas crenças, é tão somente uma fisiognomia. Não corrobora nenhuma hipótese sobre a essência do pensamento, sobre a racionalidade da comunicação, nem, por outro lado, sobre a incomensurabilidade dos paradigmas, sobre o relativismo ou sobre a natureza fundamental da realidade. A pergunta pelo excluído, pelo diferente, começa pela etnografia das nossas categorizações e do nosso correlativo sentimento de estranheza.

\section{Referências:}

COHEN, Henri \& LEFEBVRE, Claire (eds.). Handbook of Categorization in Cognitive Science. Amsterdam: Elsevier, 2005.

DAVIDSON, Donald. On the Very Idea of a Conceptual Scheme. In: Inquiries into Truth and Interpretation. Oxford: Clarendon Press, p. 183-198, 1984.

FESTINGER, Leon. A Theory of Cognitive Dissonance. Stanford: Stanford University Press, 1957.

FEYERABEND, Paul. Explanation, Reduction and Empiricism. In: FEIGL, Herbert \& MAXWELL, Grover (eds.). Scientific Explanation, Space, and Time. Minneapolis: University of Minneapolis Press, p. 28-97, 1962.

HABERMAS, Jürgen. Theorie des kommunikativen Handelns. Band I: Handlungsrationalität und gesellschaftliche Rationalisierung. Zweite Auflage. Frankfurt am Main: Suhrkamp, 1982.

IRVINE, Andrew. Philosophy of Logic. In: SHANKER, Stuart (ed.). Philosophy of Science, Logic and Mathematics in the 20 ${ }^{\text {th }}$ Century. London: Routledge, p. 9-49, 1996.

KANT, Immanuel. Crítica da Razão Pura. $2^{\mathrm{a}}$ edição. Tradução de Manuela P. dos Santos e Alexandre F. Morujão. Lisboa: Fundação Calouste Gulbenkian, 1989 [1787].

KUHN, Thomas. The Structure of Scientific Revolutions. $3^{\text {rd }}$ edition. Chicago: The University of Chicago Press, 1996 [1962].

LÉVI-STRAUSS, Claude. O Pensamento Selvagem. $8^{a}$ edição. Tradução de Tânia Pellegrini. Campinas: Papirus Editora, 2008 [1962].

MILL, John S. An Examination of Sir William Hamilton's Philosophy. Toronto: University of Toronto Press, 1979 [1873].

PENROSE, Roger. The Emperor's New Mind. Oxford: Oxford University Press, 1989.

QUINE, Willard v. O. Two Dogmas of Empiricism. In: From a Logical Point of View. New York: Harper \& Row, 1953, p. 20-46.

SCHWITZGEBEL, Eric. Belief. In: ZALTA, Edward N. (ed.) The Stanford Encyclopedia of Philosophy. Disponível em: https://plato.stanford.edu/entries/belief/ . Acesso em 03/09/2019. 
SIPSER, Michael. Introduction to the Theory of Computation. $3^{\text {rd }}$ edition. Boston: Cengage Learning, 2013.

TURING, Alan. On Computable Numbers, with an Application to the Entscheidungsproblem. Proceedings of the London Mathematical Society v. 42, n. 1, p. 230-265, 1936.

TYCHO BRAHE FRAMEWORK. Kadiwéu: História de Antigamente. Disponível em: http://www.tycho.iel.unicamp.br/fmk/index . Data de acesso: 10/09/2019.

VINHA, Marina. Memórias do Guerreiro, Sonhos de Atleta: Jogos Tradicionais e Esportes entre Jovens Kadiwéu. Dissertação (mestrado). Campinas: Unicamp, 1999.

WITTGENSTEIN, Ludwig. Observações Sobre o Ramo Dourado de Frazer. Tradução de João José R. L. de Almeida. Porto: Deriva Editores, 2011.

\section{Correspondência}

João José R. L. de Almeida: é professor associado na Escola de Ciências Aplicadas da Universidade Estadual de Campinas, Brasil.

ORCID: 0000-0002-9497-525X

E-mail: joaojose@unicamp.br

Texto publicado em Currículo sem Fronteiras com autorização do autor. 